\title{
Hydrosalpinx and IVF: Effect and Management
}

\author{
Akmal El-Mazny, MD, FICS* \\ Department of Obstetrics and Gynecology, Faculty of Medicine, Cairo University, Egypt
}

*Corresponding Author: Akmal El-Mazny, MD, FICS, Department of Obstetrics and Gynecology, Faculty of Medicine, Cairo University, Egypt,Email: dr_akmalelmazny@yahoo.com

\begin{abstract}
Patients with a hydrosalpinx have been found to have significantly poorer IVF outcome than do patients with tubal factor infertility but no hydrosalpinx. The exact mechanism by which hydrosalpingial fluid impacts implantation and pregnancy is not clear; however, many theories exist. The rationale behind treatment of hydrosalpinx prior to IVF is to eliminate the detrimental effect of hydrosalpingel fluid either by removing the fallopian tube (salpingectomy) or by isolating it from the uterine cavity (laparoscopic or hysteroscopic occlusion, or Essure insert), or by aspirating the hydrosalpingel fluid (ultrasound-guided).
\end{abstract}

Keywords: Hydrosalpinx, IVF

\section{INTRODUCTION}

Tubal factor infertility accounts for up to $35 \%$ of female infertility, and was one of the original motivations for the development of in-vitro fertilization (IVF) [1].

Hydrosalpinx is defined as fluid collection in a blocked fallopian tube, and is found in about 10$30 \%$ of women with tubal factor infertility, corresponding to approximately $5 \%$ of infertile women [2].

Hydrosalpinx is associated with a large reduction in pregnancy rates following IVF (about 40-50\%), and an increased risk of miscarriage and ectopic pregnancy [3].

This review discusses the effect of hydrosalpinx on IVF and the lines of management of hydrosalpinx before IVF.

\section{DISCUSSION}

\subsection{Effect of Hydrosalpinx on IVF}

Patients with a hydrosalpinx have been found to have significantly poorer IVF outcome than do patients with tubal factor infertility but no hydrosalpinx [4].

The exact mechanism by which hydrosalpingial fluid impacts implantation and pregnancy is not clear; however, many theories exist.

The harmful effect of a hydrosalpinx on pregnancy after IVF has been attributed to mechanical washout of the transferred embryos by tubal-uterine reflux of the hydrosalpingel fluid [5].
Hydrosalpingel fluid may contain inflammatory mediators such as cytokines, prostaglandins, and mucosal debris that may be toxic to the implanting embryo [6].

The presence of hydrosalpingel fluid in the endometrial cavity physically inhibits implantation and impairs the expression of factors essential for the development and differentiation of the endometrium, such as integrins (the best endometrial receptivity markers) [7].

Hydrosalpinx may be also associated with impaired endometrial and ovarian blood flows which may adversely affect endometrial receptivity and oocyte quality [8].

\subsection{Management of Hydrosalpinx before IVF}

The rationale behind treatment of hydrosalpinx prior to IVF is to eliminate the detrimental effect of hydrosalpingel fluid either by removing the fallopian tube (salpingectomy) or by isolating it from the uterine cavity (laparoscopic or hysteroscopic occlusion, or Essure insert), or by aspirating the hydrosalpingel fluid (ultrasound-guided) [9].

Laparoscopic surgery, including salpingectomy or tubal occlusion, has been shown to improve IVF outcome for patients with a hydrosalpinx [10]. However, this procedure has many drawbacks, including its invasiveness, technical difficulty if there are pelvic adhesions, the possibility of surgical injury (e.g. visceral injury, vascular damage, or unintended 
laparotomy), and the potential risks from general anesthesia [11].

There are also some concerns about salpingectomy, including its potentially negative effect on the ovarian blood flow and subsequent reduction of ovarian response to gonadotropin stimulation, and its permanent nature, which precludes any possibility of spontaneous conception in the future in cases of bilateral salpingectomy [12].

Proximal tubal occlusion of a hydrosalpinx by hysteroscopy (either an Essure insert or electrocoagulation) might offer a feasible therapeutic alternative when laparoscopy is technically difficult or contraindicated [13].

Although an Essure device is an effective method for sterilization, there is some apprehension regarding its use in the treatment of a hydrosalpinx before IVF. In addition to the cost of the device, the Essure coil might trail into the uterine cavity, with possible effects on both implantation and pregnancy, and the nickel titanium elastic outer coil might affect the developing embryo [14-16].

Hysteroscopic tubal electrocoagulation might be a possible alternative to the Essure device for hydrosalpinx treatment before IVF. However, hysteroscopic monopolar surgery is associated with both the potential risk of electrosurgical injury and complications of distending media $[17,18]$.

Aspiration of hydrosalpingel fluid is less invasive and easier to perform in cases of dense pelvic adhesions. However, its main disadvantages are the high recurrence rate of hydrosalpinx and the possibility to flare up pelvic infections [19].

\section{CONClusion}

A recent overview of Cochrane reviews [20] concluded that:

- Surgical treatment should be considered for all women with hydrosalpinges before IVF treatment.

- Both laparoscopic salpingectomy and tubal occlusion before IVF increase the chances of clinical pregnancy (moderate-quality evidence).

- Laparoscopic tubal occlusion is an alternative to laparoscopic salpingectomy for improving pregnancy rates among women with hydrosalpinges undergoing IVF.
- Evidence is insufficient to allow assessment of the value of aspiration of hydrosalpinges before or during IVF procedures (very lowquality evidence) or the value of tubal restorative surgery as an alternative (or as apreliminary) to IVF.

\section{REFERENCES}

[1] Strandell A, Lindhard A,WaldenströmU, Thorburn J. Hydrosalpinx and IVF outcome: cumulative results after salpingectomy in a randomized controlled trial. Hum Reprod. 2001; 16(11): 2403-10.

[2] D'Arpe S, Franceschetti S, Caccetta J, Pietrangeli D, Muzii L1, Panici PB. Management of hydrosalpinx before IVF: a literature review. J Obstet Gynaecol. 2015; 35(6): 547-50.

[3] Practice Committee of American Society for Reproductive Medicine in collaboration with Society of Reproductive Surgeons. Salpingectomy for hydrosalpinx prior to in vitro fertilization. Fertil Steril. 2008; 90(Suppl. 5): S66-8.

[4] Puttemans P, Campo R, Gordts S, Brosens I. Hydrosalpinx and ART: hydrosalpinxfunctional surgery or salpingectomy? Hum Reprod. 2000; 15(7): 1427-30.

[5] Mijatovic V, Veersema S, Emanuel MH, Schats R, Hompes PG. Essure hysteroscopic tubal occlusion device for the treatment of hydrosalpinx prior to in vitro fertilizationembryo transfer in patients with a contraindication for laparoscopy. Fertil Steril. 2010; 93(4): 1338-42.

[6] Koong MK, Jun JH, Song SJ, Lee HJ, Song IO, Kang IS. A second look at the embryotoxicity of hydrosalpingeal fluid: an in-vitro assessment in a murine model. Hum Reprod. 1998; 13(10): 2852-6.

[7] Savaris RF, Pedrini JL, Flores R, Fabris G, Zettler CG. Expression of $\alpha 1$ and $\beta 3$ integrins subunits in the endometrium of patients with tubal phimosis or hydrosalpinx. Fertil Steril. 2006; 85(1): 188-92.

[8] El-Mazny A, Ramadan W, Kamel A, GadAllah S. Effect of hydrosalpinx on uterine and ovarian hemodynamics in women with tubal factor infertility. Eur J Obstet Gynecol Reprod Biol. 2016; 199: 55-9

[9] Johnson N, van Voorst S, Sowter MC, Strandell A, Mol BW. Surgical treatment for tubal disease in women due to undergo in vitro fertilisation. Cochrane Database Syst Rev. 2010; 1: CD002125.

[10] Johnson NP, MakW, Sowter MC. Surgical treatment for tubal disease in women due to undergo in vitro fertilisation. Cochrane Database Syst Rev. 2004; 3: CD002125. 
[11] Practice Committee of the American Society for Reproductive Medicine. Salpingectomy for hydrosalpinx prior to in vitro fertilization. Fertil Steril. 2004; 82(Suppl. 1): S117-9.

[12] Orvieto R, Saar-Ryss B, Morgante G, Gemer O, Anteby EY, Meltcer S. Does salpingectomy affect the ipsilateral ovarian response to gonadotropin during in vitro fertilization-embryo transfer cycles? Fertil Steril. 2011; 95(5):1842-4.

[13] Ozgur K, Bulut H, Berkkanoglu M, Coetzee K, Kaya G. ICSI pregnancy outcomes following hysteroscopic placement of Essure devices for hydrosalpinx in laparoscopic contraindicated patients. Reprod Biomed Online. 2014; 29(1): 113-8.

[14] Kerin JF, Cattanach S. Successful pregnancy outcome with the use of in vitro fertilization after Essure hysteroscopic sterilization. Fertil Steril. 2007; 87(5): 1212. e1-4.

[15] Hitkari JA, Singh SS, Shapiro HM, Leyland N. Essure treatment of hydrosalpinges. Fertil Steril. 2007; 88(6): 1663-6.

[16] Galen DI. Utilization of the Essure ${ }^{\circledR}$ microinsert for the treatment of hydrosalpinx prior to in vitro fertilization. Fertil Steril. 2007; 88(Suppl. 1): S16.

[17] Aboulghar MM, Azmy O, Nada A, Shawky O, Mostafa H. Hysteroscopic tubal electrocoagulation in cases with communicating hydrosalpinx and planning for IVF_ - a pilot study. Int J Med. 2008; 1(2): 81-5.

[18] El-Mazny A, Abou-Salem N, Hammam M, Saber W. Hysteroscopic tubal electrocoagulation versus laparoscopic tubal ligation for patients with hydrosalpinges undergoing in vitro fertilization. Int $\mathbf{J}$ Gynaecol Obstet. 2015; 130(3): 250-2

[19] Hammadieh N, Coomarasamy A, Ola B, Papaioannou S, Afnan M, Sharif K. Ultrasound-guided hydrosalpinx aspiration during oocyte collection improves pregnancy outcome in IVF: a randomized controlled trial. Hum Reprod. 2008; 23(5): 1113-7.

[20] Farquhar C, Marjoribanks J. Assisted reproductive technology: an overview of Cochrane Reviews. Cochrane Database Syst Rev. 2018; 8: CD010537.

Citation: Akmal El-Mazny. Hydrosalpinx and IVF: Effect and Management. ARC Journal of Gynecology and Obstetrics. 2019; 4(1):21-23. DOI:dx.doi.org/10.20431/2456-0561.0401004.

Copyright: (c) 2019 Authors. This is an open-access article distributed under the terms of the Creative Commons Attribution License, which permits unrestricted use, distribution, and reproduction in any medium, provided the original author and source are credited. 